Title: Ecological stoichiometry meets ecological engineering: Using algal polycultures to enhance the multifunctionality of algal biocrude systems

Authors: Casey M. Godwin*, School for Environment and Sustainability, University of Michigan, cgodwin@umich.edu; David C. Hietala, Department of Chemical Engineering, University of Michigan, hietala@umich.edu; Aubrey R. Lashaway, School for Environment and Sustainability, University of Michigan, aubrain@umich.edu; Anita Narwani, Eawag, Swiss Federal Institute of Aquatic Science and Technology, anita.narwani@eawag.ch; Phillip E.

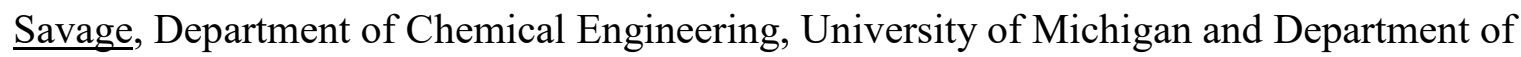
Chemical Engineering, Pennsylvania State University, psavage@engr.psu.edu; Bradley J.

Cardinale, School for Environment and Sustainability, University of Michigan, bradcard@umich.edu

*Corresponding author, cgodwin@umich.edu, University of Michigan, 440 Church Street, Ann Arbor, MI 48109, USA, Phone 651.328.4557, Fax 1.734.763.3603.

\begin{abstract}
For algal biofuels to be economically sustainable and avoid exacerbating nutrient pollution, algal cultivation and processing must maximize rates of biofuel production while simultaneously minimizing the consumption of nitrogen $(\mathrm{N})$ and phosphorus $(\mathrm{P})$ fertilizers. We experimentally tested whether algal polycultures could be engineered to improve $\mathrm{N}$ - and P- nutrient-use efficiency compared to monocultures by balancing trade-offs in nutrient-use efficiency and biocrude production. We analyzed the flows of $\mathrm{N}$ and $\mathrm{P}$ through the processes of cultivation, biocrude production through hydrothermal liquefaction, and nutrient recycling in a laboratoryscale system. None of the six species we examined exhibited high N-efficiency, P-efficiency and This document is the accepted manuscript version of the following article: Godwin, C. M., Hietala, D. C., Lashaway, A. R., Narwani, A., Savage, P. E., \& Cardinale, B. J. (2017). Ecological stoichiometry meets ecological engineering: using polycultures to enhance the multifunctionality of algal biocrude systems. Environmental Science and Technology, 51(19), 11450-11458. https://doi .org/10.1021/acs.est.7b02137
\end{abstract}


biocrude production simultaneously; each had poor performance in at least one function (i.e. < $25^{\text {th }}$ percentile). Polycultures of 2 to 6 species did not outperform the best species in any single function, but some polycultures exhibited more balanced performance and maintained all three functions at higher levels simultaneously than any of the monocultures (i.e. $>67^{\text {th }}$ percentile). Moreover, certain polycultures came closer to optimizing all three functions than any of the monocultures. By balancing trade-offs between N- and P-efficiency and biocrude production, polycultures could be used to simultaneously reduce the demand for both $\mathrm{N}$ and $\mathrm{P}$ fertilizers by up to $85 \%$.

\section{TOC Art}

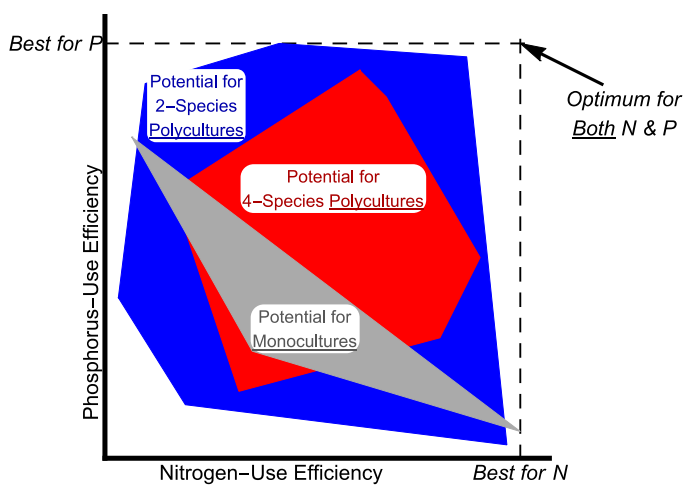




\section{INTRODUCTION}

The development of sustainable biofuel systems will require maximizing energy production while simultaneously minimizing the use of limited resources like arable land, water, and nutrient fertilizers. Compared to terrestrial biofuel crops, algal biofuels are often cited as a promising source of renewable energy because they have substantially higher areal rates of productivity, thus requiring a smaller amount of land per unit of fuel output ${ }^{1}$. However, algae have higher tissue nitrogen $(\mathrm{N})$ and phosphorus $(\mathrm{P})$ content than terrestrial plants ${ }^{2}$, which translates into greater demand for these nutrients for the same amount of biomass production. Therefore, a key challenge in the development of algal biofuel systems is to minimize the amount of fertilizer consumed per unit fuel produced. Improvements in the nutrient budget would make algae-based fuel more economically competitive, decrease competition for fertilizer supplies that are presently used to grow food crops, and reduce the potential for algal cultivation to exacerbate nutrient pollution.

Engineering the production of algal feedstocks and biofuel (as carbon, C) while minimizing the consumption of $\mathrm{N}$ and $\mathrm{P}$ can benefit from the application of ideas from the field of 'ecological stoichiometry' ${ }^{3}$ to the renewable energy industry. Ecological stoichiometry describes ecological interactions in terms of the relative proportions of chemical elements and energy in biomass, metabolism, and the environment. Several studies and life cycle assessments (LCAs) have already used algal biomass C:N:P stoichiometry to estimate the fertilizer requirements of cultivating algal feedstocks ${ }^{4-6}$. These LCAs commonly assume that the elemental composition of algae is constant, and equal to the Redfield ratio of 106C: 16N: 1P for marine plankton ${ }^{7}$. Studies using this assumption predict that replacing diesel fuel consumption with algal biofuel would use more fertilizer $\mathrm{N}$ and $\mathrm{P}$ than is presently used for agriculture ${ }^{6}$. 
However, the biomass $\mathrm{C}: \mathrm{N}: \mathrm{P}$ of algae is highly variable among species ${ }^{8}$ and in response to growing conditions ${ }^{9,10}$. Indeed, the data available for algal biofuel cultures show that $\mathrm{C}: \mathrm{N}$ ratios can range from 4.8 to 26:1 and C:P from 27 to 143:1 (see Supporting Information Table S1). If algal biofuel cultures have biomass C:N and/or C:P ratios below the Redfield ratio (i.e. more Nand P-rich), actual fertilizer demand will be higher than has been estimated. However, even if biofuel cultures have somewhat higher C:N and C:P than the Redfield ratio (less $\mathrm{N}$ - and P-rich), then fertilizer demands are still an obstacle to the feasibility and sustainability of producing algal biofuel.

The amount of nutrients required to grow each unit of algal feedstock biomass can only be reduced by two means: (1) increasing the C:nutrient ratio of the algal biomass and/or by (2) recycling nutrients following conversion of biomass to biocrude. Nutrient demand could be improved by selecting species with high C:nutrient ratios ${ }^{11,12}$. However, because species that grow quickly have high biomass $\mathrm{N}$ and $\mathrm{P}$ content ${ }^{13}$, there is potential for trade-offs among species in terms of their productivity and demand for nutrients. Nutrient limitation causes some species of algae to increase their biomass $\mathrm{C}: \mathrm{N}$ and $\mathrm{C}: \mathrm{P}^{9}$ and $\mathrm{N}$-limitation causes some algae to accumulate lipids that can be extracted to produce biodiesel ${ }^{14}$. But, by definition, nutrient limitation means that growth rates and yields are reduced compared to nutrient-replete conditions. As an alternative to direct lipid extraction, hydrothermal liquefaction (HTL) is a process that converts wet algal biomass to biocrude oil, an energy-dense fuel precursor that can be catalytically upgraded to mirror the properties of crude oil ${ }^{15}$. Because HTL does not require biomass with high lipid content, the algae for HTL feedstock can be grown under nutrient-replete conditions to maximize their rates of total biocrude production. 
Recycling nutrients after biofuel production would substantially decrease the fertilizer demand of algal biofuels ${ }^{16}$. During HTL up to $80 \%$ of the $\mathrm{N}$ and P in algal biomass is converted to ammonium and phosphate that resides in an aqueous-phase coproduct (ACP) that is derived from the water used in the HTL reaction ${ }^{17}$. The nutrient-rich ACP can potentially be recycled back into the depleted culture medium to replenish nutrients (Figure 1). Although direct ACP recycling could decrease the demand for fertilizer inputs, exposure to ACP has been shown to kill or inhibit the growth of some algae ${ }^{18,19}$. The inhibitory effects of ACP could negate the benefit from nutrient recycling, but recent work has shown that some species are more tolerant of $\mathrm{ACP}$ recycling ${ }^{20-22}$ and that some polycultures can exhibit enhanced growth in the presence of $\mathrm{ACP}^{23}$.

Identifying species or engineering polycultures that optimize both productivity and nutrient-use efficiency is a key step toward improving both economic feasibility and environmental sustainability of algal biocrude production. Numerous studies have shown that diverse polycultures of algae and terrestrial plants can produce more biomass than the average of their component species grown in monoculture ${ }^{24}$. Although polycultures less frequently outperform the best species ${ }^{25}$, positive biodiversity-productivity relationships have inspired researchers to ask whether biodiversity could increase productivity or other aspects of algal biofuel systems ${ }^{26,27}$. Two studies showed that species richness can increase lipid yields or total cell biovolume ${ }^{12,28}$, but Narwani et al. ${ }^{29}$ recently showed that polycultures of algae did not outperform the best species in producing biocrude via HTL. Although species richness might not consistently increase biomass production, when no species is best at all functions, some polycultures can perform more functions above a given threshold than monocultures can (multifunctionality ${ }^{30}$ ). Although polycultures do not necessarily maximize any single function, 
greater multifunctionality means that polycultures can exhibit more balanced performance in terms of several functions.

In this study, we asked whether polycultures of algae could increase nutrient-use efficiency relative to monocultures and balance nutrient-use efficiency with biocrude production more effectively. We addressed this question by quantifying $\mathrm{N}$ - and $\mathrm{P}$ - nutrient-use efficiency and biocrude productivity for monocultures and polycultures of green algae grown in laboratory mesocosms and processed by HTL. We found that although polycultures generally had lower performance than the best species for any single function, they were better at balancing tradeoffs between $\mathrm{N}$ and $\mathrm{P}$ efficiency, which could be used to simultaneously reduce the demand for both $\mathrm{N}$ and $\mathrm{P}$ fertilizers.

\section{MATERIALS AND METHODS}

\section{Algal cultivation and HTL}

Results presented in this paper stem from follow-up analyses of samples and data collected during a previous study that examined biomass cultivation and biocrude production by algal monocultures and polycultures using fresh nutrients ${ }^{29}$. Whereas the previous study examined the impact of diversity on the productivity and temporal stability of cultivation, in the present study we focus of the potential for biodiversity to improve the nutrient use efficiency during cultivation, HTL processing, and recycling. The pertinent details of the previous experiment are summarized here. Six species of green microalgae were selected for the study based on the criteria that they (1) are among the most common species found in North American lakes ${ }^{31},(2)$ were part of the U.S. Department of Energy's Aquatic Species Program, and (3) have been shown to enhance biomass production when grown as polycultures ${ }^{32}$. The species and 
their letter codes are: Ankistrodesmus falcatus A; Chlorella sorokiniana B; Pediastrum duplex C; Scenedesmus acuminatus D; Scenedesmus ecornis E; and Selenastrum capricornutum F. The experiment was performed in two temporal blocks, each with a factorial design of species composition and temperature regime. The species compositions included all six monocultures (3 replicates each), 15 two-species polycultures ( 2 replicates each), 15 four-species polycultures ( 2 replicates each), and the six-species polyculture (9 replicates). Algae were inoculated into experimental units using a substitutive design where the total initial cell density of $12,000 \mathrm{~mL}^{-1}$ was the same for all levels of species richness. Experimental units were randomly assigned to either a constant $\left(22^{\circ} \mathrm{C}\right)$ or variable water temperature treatment. In the variable temperature treatment, water temperature was changed each week from $17^{\circ} \mathrm{C}$ to $27^{\circ} \mathrm{C}$ to simulate changing environmental conditions like weather fronts. Experimental units were 9.5L chemostats, illuminated with $200 \mu$ moles $\mathrm{m}^{-2} \mathrm{~s}^{-1}$ from fluorescent lamps, and refreshed with growth medium at 0.3 week $^{-1}$. The growth medium was Bold-3N medium ${ }^{33}$, containing 8.82 mmoles- $\mathrm{N} \mathrm{L}^{-1}$ as nitrate and 1.72 mmoles-P $L^{-1}$ as phosphate.

After the cultures attained steady-state biomass, they were maintained for 7 weeks. During this period, cultures were sampled weekly and the algal biomass was concentrated through settling, centrifuging, and drying at $60^{\circ} \mathrm{C}$. For conversion to biocrude, the dried biomass was mixed with deionized water to $5 \%$ solids content (by mass) and subjected to hydrothermal liquefaction (HTL) performed at $350^{\circ} \mathrm{C}$ for 20 minutes ${ }^{17}$. The aqueous-phase co-product (ACP) from HTL was frozen at $-20^{\circ} \mathrm{C}$ prior to analysis.

\section{Calculating net nutrient-use efficiency}

Quantifying the impact of nutrient recycling on fertilizer demand requires that we consider both the nutrient content of algal biomass and the efficiency of recycling. Nutrient-use 
efficiency has been previously defined as the amount of biomass or $\mathrm{C}$ gained relative to the amount of nutrients incorporated in tissue during growth ${ }^{3,34}$. While this previous definition is relevant for understanding biomass yields in a single harvest, some modification is necessary when nutrients are recycled and used repeatedly through time to grow more biomass. Here, we define net nutrient-use efficiency (nNUE) as the molar ratio of biomass $\mathrm{C}$ harvested to the net loss of biomass $\mathrm{N}$ or $\mathrm{P}$ during biocrude production and recycling. The recovery efficiency (RE) is the proportion of biomass $\mathrm{N}$ or $\mathrm{P}$ that can be recovered in bio-available forms after biocrude production, and subsequently recycled into the culture medium. The nNUE can be calculated from biomass $\mathrm{C}$ content, biomass nutrient content $(\mathrm{N}$ or $\mathrm{P})$, and $\mathrm{RE}$ by the following equation:

$$
n N U E=\frac{\text { Biomass C }}{\text { Biomass nutrient }-(\text { RE } \times \text { Biomass nutrient })} \quad(\text { Equation } 1)
$$

Which simplifies to Equation 2 using the biomass C:nutrient ratio.

$$
n N U E=\frac{\text { C:nutrient }}{1-R E} \quad \text { (Equation 2) }
$$

In the absence of recycling, RE is equal to zero and the nNUE is equal to the biomass $\mathrm{C}$ :nutrient stoichiometry (Figure S1). Increasing RE causes nNUE to increase exponentially relative to the biomass C:nutrient ratio, but because complete recovery of biomass $\mathrm{N}$ or $\mathrm{P}$ after biocrude production is unlikely, RE will be less than 1. Figure 1 illustrates the calculation of RE and nNUE for algal biocrude production using HTL with direct ACP recycling. Our estimates of nNUE assume that $100 \%$ of the ACP is recycled back to the depleted culture medium. However, in a scenario with continuous ACP recycling, some fraction of the ACP may need to be purged before recycling to avoid accumulating potentially toxic or unreactive compounds, so the RE will likely be lower in practice. nNUE can be used to approximate the fertilizer inputs that would be needed for an algal biofuel production system that incorporates recycling.

\section{Nitrogen and phosphorus measurements}


To calculate the $\mathrm{N}$ - and P-nNUE for each species composition, we measured the $\mathrm{N}$ and $\mathrm{P}$ content of the algal biomass used for HTL and also the concentrations of bio-available N and P in the ACP. Our nNUE calculations are based on ammonium and phosphate since these are the predominant forms of nitrogen and phosphate in $\mathrm{ACP}$ and all of the species in our experiment can readily use these forms for growth. For each temporal block, we analyzed samples of biomass and ACP produced during the final two weeks of sampling. We measured the total $\mathrm{N}$ and $\mathrm{P}$ in dried algal biomass following digestion with alkaline persulfate ${ }^{35}$, which converts organic $\mathrm{N}$ to nitrate and organic $\mathrm{P}$ to phosphate. We performed duplicate digestions for each sample using reaction conditions of $121^{\circ} \mathrm{C}$ for 60 minutes. Cyanocobalamin was used as a recovery standard for $\mathrm{N}$ and $\mathrm{P}$. Following digestion, the phosphate concentration was determined using the molybdenum method ${ }^{36}$. Nitrate was determined by diluting the digests into phosphate buffer (100 mmoles $\left.\mathrm{L}^{-1}, \mathrm{pH} 7.4\right)$, converting the nitrate to nitrite using nitrate reductase (Nitrate Elimination Company AtNAR-RPK), then measuring the nitrite using the sulfanilamide method 36,37. For both the $\mathrm{N}$ and $\mathrm{P}$ assays, absorbance was measured in triplicate using a plate reader (BioTek Synergy H1). Biomass C content was measured in two samples from each species composition by $\mathrm{CHN}$ analysis (Atlantic Microlab, Inc.).

To quantify the bio-available forms of $\mathrm{N}$ and $\mathrm{P}$ in the $\mathrm{ACP}$, we separately measured the phosphate, ammonium, and nitrate concentrations in ACP using a plate reader. Nitrate concentration in the ACP was measured using the nitrate reductase and colorimetric method described for biomass $\mathrm{N}$. The mean nitrate concentration in samples within detection was 382 $\mu$ moles $\mathrm{L}^{-1}$; however, more than $97 \%$ of the samples measured for nitrate fell below the detection limit (156 to $240 \mu$ moles $\mathrm{L}^{-1}$ ). Phosphate concentration in diluted ACP was measured using the method described for digest P. Ammonium in the diluted ACP was measured using the 
fluorescent pthaldialdehyde method ${ }^{38}$ and standard additions were used to account for matrix effects ${ }^{39}$. None of the phosphate or ammonium samples were below the $99 \%$ confidence detection limits determined from method blanks ${ }^{36}$. For each mono- and polyculture, we calculated the molar biomass $\mathrm{C}: \mathrm{N}, \mathrm{C}: \mathrm{P}$, and $\mathrm{N}: \mathrm{P}$ ratios using the mean dry mass content for each element. For each stoichiometric ratio, we used the mean and standard error for the numerator and denominator elements to calculate the expected standard error of the ratio, following the delta method for propagation of error in division ${ }^{3}$.

For individual HTL reactions, we calculated the recovery efficiency $(\mathrm{RE})$ as the proportion of feedstock $\mathrm{N}$ or $\mathrm{P}$ that was converted to ammonium or phosphate in the $\mathrm{ACP}$. The total amount of $\mathrm{N}$ or $\mathrm{P}$ in the feedstock was estimated by multiplying the percent $\mathrm{N}$ or $\mathrm{P}$ measured in the dry algae by the total mass of algae used in the reaction. The total amount of bio-available $\mathrm{N}$ or $\mathrm{P}$ in the $\mathrm{ACP}$ was estimated by multiplying the concentration of ammonium or phosphate in the ACP by the volume of ACP recovered. Net nutrient-use efficiency (nNUE) was calculated following Equation 2, using the mean recovery efficiency and biomass stoichiometry for each species composition. We quantified the potential for biocrude production as the mass of biocrude produced per liter of culture, averaged across blocks and dates ${ }^{29}$. Biocrude productivity ranged from 12 to $430 \mathrm{mg}$ biocrude $\mathrm{L}^{-1}$ and was strongly correlated with mean biomass productivity $\left(\mathrm{r}^{2}=0.98\right)$. Six species compositions $(\mathrm{A}, \mathrm{C}, \mathrm{E}, \mathrm{AC}, \mathrm{AE}$, and $\mathrm{CE})$ had very low biocrude production $\left(<25 \mathrm{mg} \mathrm{L}^{-1}\right)$ and were excluded from analyses of nNUE.

\section{Statistical analyses}

We performed linear mixed models using species richness, species composition (nested in species richness), and growth temperature treatment as fixed effects and temporal block and experimental unit as random effects (using the R function 'Imer', package lme4). Response 
variables were biomass $\mathrm{N}$ and $\mathrm{P}$ content, $\mathrm{ACP} \mathrm{N}$ and $\mathrm{P}$ content, and recovery efficiencies for $\mathrm{N}$ and P. Response variables were log-transformed to meet the assumptions of homogeneity of variances and approximate normality. We discarded the random effects of temporal block and/or experimental unit when they did not significantly improve the Akaike information criterion (AIC). We performed post hoc comparisons between each polyculture and each of its component species using the R packages 'predictmeans' for ordinary linear models and 'ImerTest' for linear mixed models.

To evaluate potential trade-offs among N-nNUE, P-nNUE, and biocrude production, we used the concept of multifunctionality that was recently developed for studying how biodiversity influences multiple ecological functions simultaneously ${ }^{30,40}$. This method does not rely upon subjective weighting of each function, but instead allows for analysis of trade-offs in terms of relative performance. To standardize the scales for each function, we ranked all of the species compositions and divided each rank by the total number of species compositions with available data $(n=31)$. The superior species composition for a given function has rank 1 and the composition with the lowest performance has rank $1 / 31$.

Each species composition can be represented in a three-dimensional space where the axes are performance ranks for: biocrude productivity, N-nNUE, and P-nNUE. We characterized three different aspects of multifunctionality in this three-dimensional space. Distance from optimum is defined as the Euclidean distance between the multi-function performance ranks for a given species composition and the point where all three ranks are equal to 1 , which represents the maximum possible multi-function performance for all species compositions. Smaller distances from optimum indicate that the multi-function performance is closer to the overall maximum whereas large distances indicate poor performance in at least one function. Performance 
imbalance is defined as the Euclidean distance between the multi-function performance ranks for a given species composition and the multi-function 1:1:1 line. Larger values of performance imbalance suggest strong trade-offs in the ability of species compositions to perform the three functions, whereas smaller values indicate more balanced performance across the three functions. Maximum performance threshold is defined as the highest performance rank at which a species composition can perform all three functions simultaneously. For each species composition there is only one value of maximum performance threshold. For example, a composition with performance ranks of $0.2,0.8$, and 0.9 has a maximum performance threshold of 0.2 . This metric is similar to the multifunctionality index developed by Byrnes et al. ${ }^{40}$, but differs in that all three functions must exceed the threshold. For each level of species richness $(1,2,4$, or 6$)$, we manipulated the threshold between 0 and 1 by increments of 0.01 and counted the number of species compositions that sustained all three functions at a rank greater than the threshold.

\section{RESULTS}

\section{Biomass elemental content}

Figure 2 shows that most of the species compositions exhibited C:N:P stoichiometry that was different from the Redfield ratio - often vastly different. For all of the mono- and polycultures (100\%), mean biomass C:N was more than one standard error higher than the Redfield ratio. Most of the species compositions (84\%) had lower C:P than the Redfield ratio and nearly all of the compositions (94\%) exhibited lower mean N:P than the Redfield ratio. These data show that for culture conditions used in this experiment, monocultures and polycultures of algae exhibit highly variable biomass stoichiometry with elemental composition that does not 
reflect the Redfield ratio, as is commonly assumed in lifecycle assessments of algal biofuel cultivation.

Figure $\mathrm{S} 2$ shows that there was a significant negative relationship between nitrogen $(\mathrm{N})$ and phosphorus $(\mathrm{P})$ content in the biomass of algae (linear regression $\mathrm{p}<0.01, \mathrm{r}^{2}=0.26$ ). Both $\mathrm{N}$ and $\mathrm{P}$ content differed significantly among levels of species richness and among different species compositions (Table S2), but there was no significant effect of the growth temperature treatment ( $>0.25$ for constant vs. variable water temperatures). Among the monocultures, mean biomass $\mathrm{N}$ content was highest in Chlorella (B, 7.8\%) and lowest in Selenastrum (F, 4.0\%), and mean biomass P content was highest in Scenedesmus ecornis (E, 3.1\%) and lowest in Chlorella (B, $1.1 \%)$.

\section{Recovery efficiency and nNUE}

Figure 3 shows the relationship between biomass stoichiometry (x-axes), recovery efficiency (dashed lines), and nNUE for N and P (y-axes) for various species compositions. Concentrations of $\mathrm{N}$ and $\mathrm{P}$ in $\mathrm{ACP}$ were strongly correlated with the $\mathrm{N}$ and $\mathrm{P}$ content of biomass $\left(\mathrm{r}^{2}=0.69\right.$ for $\mathrm{N}, \mathrm{r}^{2}=0.91$ for $\left.\mathrm{P}\right)$ and showed significant effects of species richness and species composition, but not growth temperature treatments (Figure S3). Recovery efficiency for P ranged from 70 to $90 \%$ and did not show significant effects of species richness, species composition, or growth temperature treatment (Table S2). Recovery efficiency for $\mathrm{N}$ ranged from 60 to $85 \%$ and showed significant differences among species compositions, with higher RE in compositions containing Selenastrum (F). Overall, N-nNUE ranged from 19:1 to 90:1 and PnNUE ranged between 198:1 and 860:1 among the species compositions (Figure 3). None of the polycultures exhibited higher N-NUE than the best monoculture for N (Selenastrum, F), but 7 of 28 polycultures had higher P-nNUE than the best monoculture for $\mathrm{P}$ (Chlorella, B). These data 
show that no single species was most efficient at retaining both $\mathrm{N}$ and $\mathrm{P}$. Rather, the two best species in terms of nNUE had strongly opposing profiles: Selenastrum was efficient in N but inefficient in P (N-nNUE=90:1, P-nNUE=201:1) and Chlorella showed high P efficiency but low $\mathrm{N}$ efficiency $(\mathrm{N}-\mathrm{nNUE}=21: 1, \mathrm{P}-\mathrm{nNUE}=463)$.

\section{Performance trade-offs in nNUE and biocrude production}

There was an apparent trade-off among the three most productive monocultures in terms of their N-nNUE and P-nNUE. Figure 4 shows the performance rank for each species composition in terms of N-nNUE (x-axis), P-nNUE (y-axis), and biocrude production (bubble diameter). Chlorella (B) had nearly the lowest N-nNUE (rank 0.06) but relatively favorable PnNUE (rank 0.78). In contrast, Selenastrum (F) had the highest N-nNUE (rank 1) and very low P-nNUE (rank 0.06). Several polycultures exhibited higher N-nNUE, P-nNUE, or both N- and PnNUE than their component species (e.g. BD, ABDF), but some of those polycultures exhibited poor performance in terms of biocrude production (e.g. ABCDEF, BCDE). There were no clear bivariate tradeoffs between biocrude productivity and nNUE for $\mathrm{N}$ or $\mathrm{P}$ (Figure S5). These data show that no single monoculture or polyculture simultaneously maximized N-nNUE, P-nNUE, and biocrude production, but that polycultures potentially offer a compromise when considering all three functions.

\section{Quantifying multifunctionality}

Overall, polycultures had higher potential for multifunctionality than the monocultures. Figure 5A shows that the three most productive monocultures (B, D, F) exhibited similar distances from optimum (i.e. the maximum possible multi-function rank). In contrast, several of the two- and four-species polycultures had smaller distances from optimum than any of the monocultures did (e.g. BD and ABDF). Figure 5B shows that compared to monocultures, 
polycultures were closer to the multi-function 1:1:1 line representing balanced performance for all three functions. This significant effect of species richness means that more diverse cultures had more balanced performance, but does not necessarily indicate that their performance was superior to monocultures for any single function or set of functions.

Figure $5 \mathrm{C}$ shows that as the threshold increases, the proportion of monocultures meeting the threshold for all three functions dropped rapidly, but the attrition was more gradual for the two- and four-species polycultures. Only one of the monocultures performed all three functions above the 0.08 rank threshold, and that species (Scenedesmus acuminatus, D) was unable to sustain all three functions above the 0.25 rank threshold. In contrast, polycultures were able to perform three functions simultaneously at higher levels than the monocultures. Half of the fourspecies polycultures met the 0.25 rank threshold and $20 \%$ of the four-species polycultures met the 0.5 threshold for all three functions. The best polyculture (ABDF) met the 0.67 threshold.

\section{DISCUSSION}

Among the mono- and polycultures examined in this study, none were able to optimize net nutrient-use efficiency for both $\mathrm{N}$ and $\mathrm{P}$. These results illustrate the potential for strong tradeoffs among species that have similar potential for growth rates and biocrude productivity ${ }^{29}$. While no single species optimized all three functions, our results show that certain polycultures offered more balanced performance for all three functions. In the following sections we discuss the potential for polycultures of algae to improve multifunctional performance in biocrude production, and the impacts of biomass stoichiometry and ACP recycling on the fertilizer demand of algal biocrude production.

Performance trade-offs in productivity and nNUE 
We used the concept of multifunctionality ${ }^{30,40}$ to analyze the apparent trade-offs among the three performance metrics. Although none of the six species could perform all three functions above the 0.25 threshold (i.e. outperform $25 \%$ of the species compositions), several of the twoand four-species polycultures displayed high potential for multifunctionality. The superior multifunctionality by polycultures means that polycultures are likely to outperform all of the monocultures in at least one function and that diverse cultures are better at balancing performance trade-offs than their component species. These outcomes are important because they mean that certain polycultures come closer to optimizing all three functions than the best single species can.

In many cases, the addition of one or more species with poor potential for biomass or biocrude production (A, C, or E) led to an increase in the nNUE of the polyculture relative to the dominant species $(\mathrm{B}, \mathrm{D}$, or $\mathrm{F})$. This result is surprising because the null expectation is that a mixture of species will have an aggregate $\mathrm{C}: \mathrm{N}: \mathrm{P}$ stoichiometry that is intermediate among the stoichiometries of each species measured in monocultures. But, if species change their biomass stoichiometry in response to competition for available nutrients or other interspecific interactions, the biomass stoichiometry and nNUE of the polyculture could be very different from any of the component species. We tested this hypothesis using post-hoc comparisons within the linear mixed models, asking whether the biomass $\mathrm{N}$ and $\mathrm{P}$ content of each polyculture was different from each of its component species. All of the polycultures showed at least one non-significant contrast with a component species ( $\mathrm{p}>0.05$ ), so our results do not support this explanation. Another possible explanation is that species richness improved recovery efficiency. Recovery efficiency for P did not differ significantly among species compositions, and although the fourspecies polycultures exhibited higher $\mathrm{RE}$ for $\mathrm{N}$ than the mean of the monocultures, none of the 
polycultures had significantly higher RE than Selenastrum (post-hoc tests, $\mathrm{p}>0.05$ ). The third possible explanation is that positive effects of species richness on biomass C:nutrient and RE, though not individually significant, caused some polycultures to exhibit higher nNUE than their component species (e.g. BD, Figure 4). This hypothesis is consistent with the multiplicative impact of biomass stoichiometry and RE on nNUE (Figure S1) and implies that even small increases in either metric can have potentially important effects on nutrient demand.

\section{Impact of biomass stoichiometry on nNUE}

Studies have suggested that fertilizer demand will be a major obstacle for algal biofuels ${ }^{6}$,

${ }^{11}$. While this is likely true, it is important to note that such estimates depend on the assumptions made about the nutrient content of algal feedstock and the efficiency of nutrient recycling. Overall, the algae in our study contained more $\mathrm{P}$ and less $\mathrm{N}$ than indicated by the Redfield ratio. While the range of biomass stoichiometry observed in our study was likely influenced by culture conditions and the restricted phylogenetic breadth of the species pool, the results were largely consistent with other measurements of biomass stoichiometry from biofuel cultures ${ }^{41,42}$, Table S1). Because the elemental composition of biomass is integral to predicting the fertilizer demands through LCAs, we recommend that further studies characterize the biomass nutrient content under conditions that mimic commercial cultivation and using species that are candidates for biofuel production.

Commercial-scale biofuel production requires algae with high growth rates that can achieve productivities in excess of $10 \mathrm{~g} \mathrm{~m}^{-2} \mathrm{~d}^{-1}$ or $0.5 \mathrm{~g} \mathrm{~L}^{-1} \mathrm{~d}^{-1} 11$. Because growth rates are positively correlated with increased biomass $\mathrm{N}$ and $\mathrm{P}$ content in algae and other organisms ${ }^{13,43}$, commercial-scale cultures will likely have high biomass $\mathrm{N}$ and $\mathrm{P}$ content. From the perspective of biocrude production using HTL, altering the biomass C:N:P of the feedstock through species 
selection or nutrient limitation could lead to conflict between nNUE and productivity. On the other hand, low biomass $\mathrm{N}$ content can lead to lower biocrude $\mathrm{N}$ content using HTL ${ }^{44}$, which

decreases costs during catalytic upgrading and refining ${ }^{45,46}$. Further research is required to determine the net impact of growth conditions, productivity, and biochemical composition across the life cycle of algal biocrude production using HTL.

\section{Impact of recycling on nNUE}

Unlike terrestrial crop cultivation, where much of the fertilizer is lost to the soil or runoff, algae are grown in semi-enclosed systems and the main source of $\mathrm{N}$ and $\mathrm{P}$ loss is during biocrude production. Thus, the recycling pathway is the principal means for reducing fertilizer requirements. ACP recycling dramatically improved nNUE relative to the biomass stoichiometry (Figure 3). This effect is particularly important because nNUE, not just the biomass stoichiometry, is the metric that describes the demand for fertilizer input. Therefore, estimates of nNUE should be included in LCAs for algal biocrude production. The range of recovery efficiency for $\mathrm{N}$ and $\mathrm{P}$ observed in our study (0.6-0.85) was similar to the findings of a previous study that used similar HTL conditions ${ }^{17}$, but we also found that RE varied among algal feedstocks. Recovery efficiency is the proportional reduction in fertilizer consumption achieved by recycling, so identifying mono- or polycultures that maximize RE and nNUE for both nutrients is an important step toward reducing fertilizer demand. Additionally, it will be important to measure nNUE under variable growth conditions that mimic commercial cultivation, and determine if and how the effects of diversity change over repeated cycles of cultivation and recycling.

Despite the importance and impact of recycling, most life cycle assessments either omit recycling or employ optimistic estimates of $\mathrm{RE}^{5,6,47,48}$. Some fraction of the biomass $\mathrm{N}$ and $\mathrm{P}$ 
that is partitioned to biocrude or solids during HTL can potentially be recovered during subsequent steps of the life cycle ${ }^{49}$, but to date there are very few studies that have empirically quantified the potential impact of this recovery ${ }^{17,44,50}$ and the feasibility of using these recovered nutrients to grow more algae is uncertain. We assumed that all of the ACP could be recycled into the culture medium, but the inhibitory effects of ACP could mean that some of the coproduct would need to be purged or diverted ${ }^{18,19}$. In a previous study we found that polycultures were not only more tolerant of ACP than monocultures (up to $10 \%$ concentration), but several polycultures exhibited enhanced growth in the presence of $\mathrm{ACP}^{23}$. This result suggests that polycultures would be able to utilize proportionally more, if not all, of the ACP produced, which would increase the nNUE for both nutrients relative to the best monocultures. Although our study does not attempt to weigh the relative importance of nNUE versus biocrude production in terms of their economic impact, the superior multifunctionality by polycultures shows that diversity could help to balance performance trade-offs. However, the favorable multifunctionality by polycultures was associated with lower performance for any single function. For example, if the only performance criteria were biocrude productivity and NnNUE, Selenastrum capricornutum (F) would simultaneously optimize both functions (Figure S5). Without a comprehensive life-cycle assessment to weigh the impact of different functions on commercial viability, trade-offs between nNUE and biocrude production can only be evaluated in terms of relative change. For example, the polyculture BD has $45 \%$ higher N-nNUE, $30 \%$ higher P-nNUE, and 24\% lower biocrude production than the mean of its component species. The relative importance and weighting of nNUE, productivity, and other performance metrics (e.g. stability, biocrude quality) ultimately requires that the integrated framework of life 
cycle assessment be informed by measurements obtained under conditions that mimic large-scale cultivation.

\section{ACKNOWLEDGMENTS}

This work was supported by NSF Grant 1332342, and a grant from the University of Michigan Energy Institute to B.J.C. Jessica Perry helped with chemical measurements on biomass and ACP.

Supporting Information Available. Figures and tables that are ancillary to the methods and results presented in the main text. This information is available free of charge via the Internet at http://pubs.acs.org.

\section{REFERENCES}

1. Chisti, Y., Biodiesel from microalgae. Biotechnology advances 2007, 25, (3), 294-306.

2. Elser, J. J.; Fagan, W. F.; Denno, R. F.; Dobberfuhl, D. R.; Folarin, A.; Huberty, A.; Interlandi, S.; Kilham, S. S.; McCauley, E.; Schulz, K. L.; Siemann, E. H.; Sterner, R. W., Nutritional constraints in terrestrial and freshwater food webs. Nature 2000, 408, (6812), 578-580.

3. Sterner, R. W.; Elser, J. J., Ecological stoichiometry: The biology of elements from molecules to the biosphere. Princeton University Press: Princeton, NJ, 2002; p 439.

4. Clarens, A. F.; Resurreccion, E. P.; White, M. A.; Colosi, L. M., Environmental life cycle comparison of algae to other bioenergy feedstocks. Environmental science \& technology 2010, $44,(5), 1813-1819$.

5. Life-cycle analysis of algal lipid fuels with the greet model; Argonne National Laboratory, E.

S. D., 2011, 
6. Pate, R.; Klise, G.; Wu, B., Resource demand implications for us algae biofuels production scale-up. Applied Energy 2011, 88, (10), 3377-3388.

7. Redfield, A. C., The biological control of chemical factors in the environment. American Scientist 1958, 46, 205-221.

8. Quigg, A.; Finkel, Z. V.; Irwin, A. J.; Rosenthal, Y.; Ho, T.-Y.; Reinfelder, J. R.; Schofield, O.; Morel, F. M.; Falkowski, P. G., The evolutionary inheritance of elemental stoichiometry in marine phytoplankton. Nature 2003, 425, (6955), 291-294.

9. Goldman, J. C.; McCarthy, J. J.; Peavey, D. G., Growth-rate influence on the chemical composition of phytoplankton in oceanic waters. Nature 1979, 279, (5710), 210-215.

10. Hillebrand, H.; Steinert, G.; Boersma, M.; Malzahn, A.; Léo Meunier, C.; Plum, C.; Ptacnik, R., Goldman revisited: Faster growing phytoplankton has lower n:P and lower stoichiometric flexibility. Limnology and Oceanography 2013, 58, (6), 2076-2088.

11. National Research Council, Committee on the Sustainable Development of Algal Biofuels, Sustainable development of algal biofuels in the united states. The National Academies Press: 2012.

12. Shurin, J. B.; Abbott, R. L.; Deal, M. S.; Kwan, G. T.; Litchman, E.; McBride, R. C.; Mandal, S.; Smith, V. H., Industrial - strength ecology: Trade - offs and opportunities in algal biofuel production. Ecology letters 2013, 16, (11), 1393-1404.

13. Nielsen, S. L.; Enriquez, S.; Duarte, C. M.; SandJensen, K., Scaling maximum growth rates across photosynthetic organisms. Functional Ecology 1996, 10, (2), 167-175.

14. Negi, S.; Barry, A. N.; Friedland, N.; Sudasinghe, N.; Subramanian, S.; Pieris, S.; Holguin, F. O.; Dungan, B.; Schaub, T.; Sayre, R., Impact of nitrogen limitation on biomass, photosynthesis, and lipid accumulation in chlorella sorokiniana. J. Appl. Phycol. 2016, 28, (2), 803-812. 
15. Duan, P.; Savage, P. E., Hydrothermal liquefaction of a microalga with heterogeneous catalysts. Ind. Eng. Chem. Res. 2011, 50, 52-61.

16. Department of Energy, United States,, National algal biofuels technology roadmap, office of energy efficiency and renewable energy biomass program. 2010.

17. Valdez, P. J.; Nelson, M. C.; Wang, H. Y.; Lin, X. N.; Savage, P. E., Hydrothermal liquefaction of nannochloropsis sp.: Systematic study of process variables and analysis of the product fractions. Biomass and Bioenergy 2012, 46, 317-331.

18. Jena, U.; Vaidyanathan, N.; Chinnasamy, S.; Das, K. C., Evaluation of microalgae cultivation using recovered aqueous co-product from thermochemical liquefaction of algal biomass. Bioresour Technol 2011, 102, (3), 3380-7.

19. Biller, P.; Ross, A. B.; Skill, S.; Lea-Langton, A.; Balasundaram, B.; Hall, C.; Riley, R.; Llewellyn, C., Nutrient recycling of aqueous phase for microalgae cultivation from the hydrothermal liquefaction process. Algal Research 2012, 1, (1), 70-76.

20. Garcia Alba, L.; Torri, C.; Fabbri, D.; Kersten, S. R. A.; Brilman, D. W. F., Microalgae growth on the aqueous phase from hydrothermal liquefaction of the same microalgae. Chemical Engineering Journal 2013, 228, 214-223.

21. Wang, S.; Shi, X.; Palenik, B., Characterization of picochlorum sp. Use of wastewater generated from hydrothermal liquefaction as a nitrogen source. Algal Research 2016, 13, 311317.

22. Selvaratnam, T.; Reddy, H.; Muppaneni, T.; Holguin, F. O.; Nirmalakhandan, N.; Lammers, P. J.; Deng, S., Optimizing energy yields from nutrient recycling using sequential hydrothermal liquefaction with galdieria sulphuraria. Algal Research 2015, 12, 74-79. 
23. Godwin, C. M.; Hietala, D.; Lashaway, A.; Narwani, A.; Savage, P. E.; Cardinale, B. J., Algal polycultures enhance coproduct recycling from hydrothermal liquefaction. Bioresour. Technol. 2017, 224, 630-638.

24. Cardinale, B. J.; Matulich, K. L.; Hooper, D. U.; Byrnes, J. E.; Duffy, E.; Gamfeldt, L.; Balvanera, P.; O'Connor, M. I.; Gonzalez, A., The functional role of producer diversity in ecosystems. Am J Bot 2011, 98, (3), 572-92.

25. Cardinale, B. J.; Srivastava, D. S.; Duffy, J. E.; Wright, J. P.; Downing, A. L.; Sankaran, M.; Jouseau, C., Effects of biodiversity on the functioning of trophic groups and ecosystems. Nature 2006, 443, (7114), 989-92.

26. Smith, V. H.; Sturm, B. S. M.; deNoyelles, F. J.; Billings, S. A., The ecology of algal biodiesel production. Trends in Ecology \& Evolution 2010, 25, (5), 301-309.

27. Newby, D. T.; Mathews, T. J.; Pate, R. C.; Huesemann, M. H.; Lane, T. W.; Wahlen, B. D.; Mandal, S.; Engler, R. K.; Feris, K. P.; Shurin, J. B., Assessing the potential of polyculture to accelerate algal biofuel production. Algal Research 2016, 19, 264-277.

28. Stockenreiter, M.; Haupt, F.; Graber, A.-K.; Seppälä, J.; Spilling, K.; Tamminen, T.; Stibor, H.; Buschmann, A., Functional group richness: Implications of biodiversity for light use and lipid yield in microalgae. Journal of Phycology 2013, 49, (5), 838-847.

29. Narwani, A.; Lashaway, A. R.; Hietala, D. C.; Savage, P. E.; Cardinale, B. J., Power of plankton: Effects of algal biodiversity on biocrude production and stability. Environ Sci Technol 2016, 50, (23), 13142-13150.

30. Lefcheck, J. S.; Byrnes, J. E.; Isbell, F.; Gamfeldt, L.; Griffin, J. N.; Eisenhauer, N.; Hensel, M. J.; Hector, A.; Cardinale, B. J.; Duffy, J. E., Biodiversity enhances ecosystem multifunctionality across trophic levels and habitats. Nature communications 2015, 6, No. 6936. 
31. Environmental Protection Agency, United States, 2007 national lakes assessment. https://www.epa.gov/national-aquatic-resource-surveys/national-lakes-assessment-2007-results 32. Fritschie, K. J.; Cardinale, B. J.; Alexandrou, M. A.; Oakley, T. H., Evolutionary history and the strength of species interactions: Testing the phylogenetic limiting similarity hypothesis. Ecology 2014, 95, (5), 1407-1417.

33. Andersen, R. A., Algal culturing techniques. Elsevier Academic Press: Oxford, UK, 2005.

34. Chapin, F. S., The mineral nutrition of wild plants. Annu. Rev. Ecol. Syst. 1980, 11, (1), 233260.

35. Methods of analysis by the u.S. Geological survey national water quality laboratoryevaluation of alkaline persulfate digestion as an alternative to kjeldahl digestion for determination of total and dissolved nitrogen and phosphorus in water; Survey, U. S. G., 2003, 36. American Public Health Association, Standard methods for the examination of water and wastewater: Including bottom sediments and sludges. 20th ed.; American Public Health Association: New York, 1995.

37. Ringuet, S.; Sassano, L.; Johnson, Z. I., A suite of microplate reader-based colorimetric methods to quantify ammonium, nitrate, orthophosphate and silicate concentrations for aquatic nutrient monitoring. $J$ Environ Monit 2011, 13, (2), 370-6.

38. Holmes, R. M.; Aminot, A.; Kerouel, R.; Hooker, B. A.; Peterson, B. J., A simple and precise method for measuring ammonium in marine and freshwater ecosystems. Can. J. Fish. Aquat. Sci. 1999, 56, (10), 1801-1808.

39. Taylor, B. W.; Keep, C. F.; Hall Jr, R. O.; Koch, B. J.; Tronstad, L. M.; Flecker, A. S.; Ulseth, A. J., Improving the fluorometric ammonium method: Matrix effects, background 
fluorescence, and standard additions. Journal of the North American Benthological Society 2007, $26,(2), 167-177$.

40. Byrnes, J. E. K.; Gamfeldt, L.; Isbell, F.; Lefcheck, J. S.; Griffin, J. N.; Hector, A.; Cardinale, B. J.; Hooper, D. U.; Dee, L. E.; Emmett Duffy, J., Investigating the relationship between biodiversity and ecosystem multifunctionality: Challenges and solutions. Methods in Ecology and Evolution 2014, 5, (2), 111-124.

41. Sturm, B. S. M.; Peltier, E.; Smith, V.; deNoyelles, F., Controls of microalgal biomass and lipid production in municipal wastewater-fed bioreactors. Environmental Progress \& Sustainable Energy 2012, 31, (1), 10-16.

42. López Barreiro, D.; Bauer, M.; Hornung, U.; Posten, C.; Kruse, A.; Prins, W., Cultivation of microalgae with recovered nutrients after hydrothermal liquefaction. Algal Research-Biomass Biofuels and Bioproducts 2015, 9, 99-106.

43. Sardans, J.; Rivas-Ubach, A.; Penuelas, J., The elemental stoichiometry of aquatic and terrestrial ecosystems and its relationships with organismic lifestyle and ecosystem structure and function: A review and perspectives. Biogeochemistry 2011, 111, (1-3), 1-39.

44. Biller, P.; Ross, A. B., Potential yields and properties of oil from the hydrothermal liquefaction of microalgae with different biochemical content. Bioresour Technol 2011, 102, (1), $215-25$.

45. Frank, E. D.; Elgowainy, A.; Han, J.; Wang, Z., Life cycle comparison of hydrothermal liquefaction and lipid extraction pathways to renewable diesel from algae. Mitigation and Adaptation Strategies for Global Change 2013, 18, (1), 137-158. 
46. Venteris, E. R.; Skaggs, R. L.; Wigmosta, M. S.; Coleman, A. M., A national-scale comparison of resource and nutrient demands for algae-based biofuel production by lipid extraction and hydrothermal liquefaction. Biomass and Bioenergy 2014, 64, 276-290.

47. Lardon, L.; Helias, A.; Sialve, B.; Steyer, J.-P.; Bernard, O., Life-cycle assessment of biodiesel production from microalgae. Environmental science \& technology 2009, 43, (17), 6475-6481.

48. Batan, L.; Quinn, J.; Willson, B.; Bradley, T., Net energy and greenhouse gas emission evaluation of biodiesel derived from microalgae. Environmental science \& technology 2010, 44, (20), 7975-7980.

49. Orfield, N. D.; Fang, A. J.; Valdez, P. J.; Nelson, M. C.; Savage, P. E.; Lin, X. N.; Keoleian, G. A., Life cycle design of an algal biorefinery featuring hydrothermal liquefaction: Effect of reaction conditions and an alternative pathway including microbial regrowth. ACS Sustainable Chemistry \& Engineering 2014, 2, (4), 867-874.

50. Levine, R. B.; Sierra, C. O. S.; Hockstad, R.; Obeid, W.; Hatcher, P. G.; Savage, P. E., The use of hydrothermal carbonization to recycle nutrients in algal biofuel production. Environmental Progress \& Sustainable Energy 2013, 32, (4), 962-975. 


\section{FIGURES}

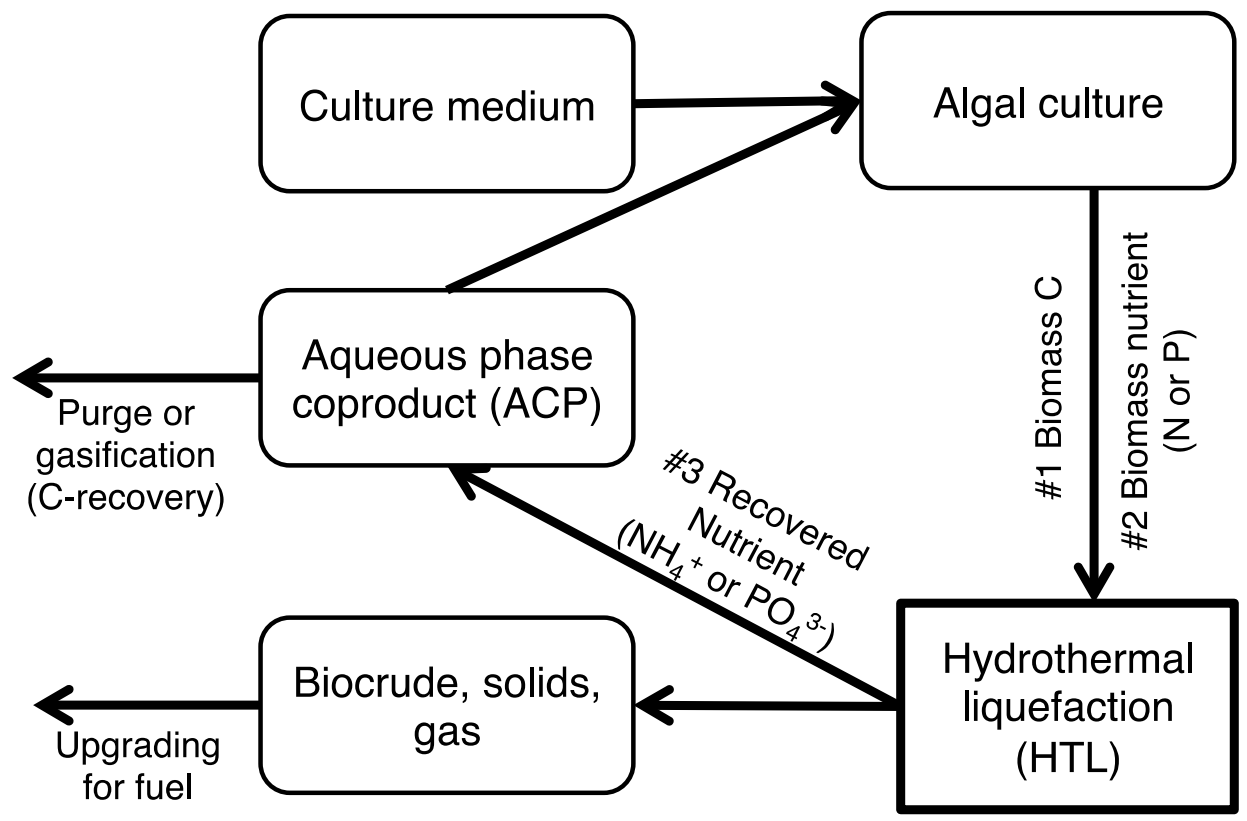

Figure 1. Schematic diagram showing the flows of biomass and nutrients in an HTL-algal

biocrude life cycle with direct recycling of the aqueous phase coproduct (ACP). In this diagram, recovery efficiency $(\mathrm{RE})$ is represented by the ratio of arrow \#3 to arrow \#2, and net nutrient-use efficiency (nNUE) is represented by \#1 / (\#2 - \#3). 

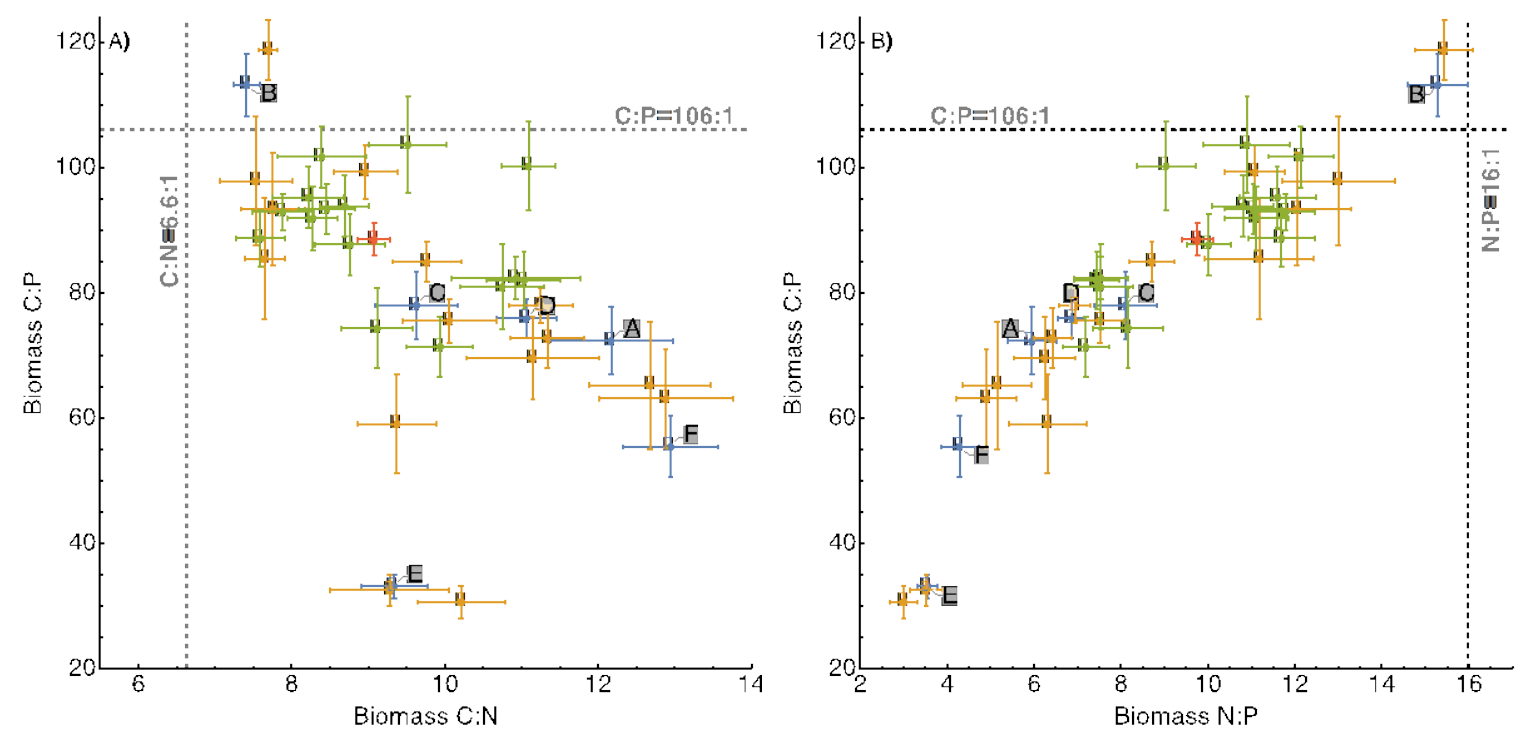

Figure 2. Molar ratios of biomass $C: P$ and $C: N(A)$, and $C: P$ and $N: P(B)$ ratios for each monoculture (labeled) and polyculture. The error bars for $\mathrm{N}$ and $\mathrm{P}$ content denote the standard error based on replicate samples. The error bars for $\mathrm{C}: \mathrm{P}, \mathrm{N}: \mathrm{P}$, and $\mathrm{C}: \mathrm{N}$ (B and $\mathrm{C}$ ) denote the standard error as calculated by the propagation of uncertainty using the standard error of the numerator and denominator elements. The dashed lines represent the Redfield ratio $(\mathrm{C}: \mathrm{N}: \mathrm{P}$ of 106:16:1). 

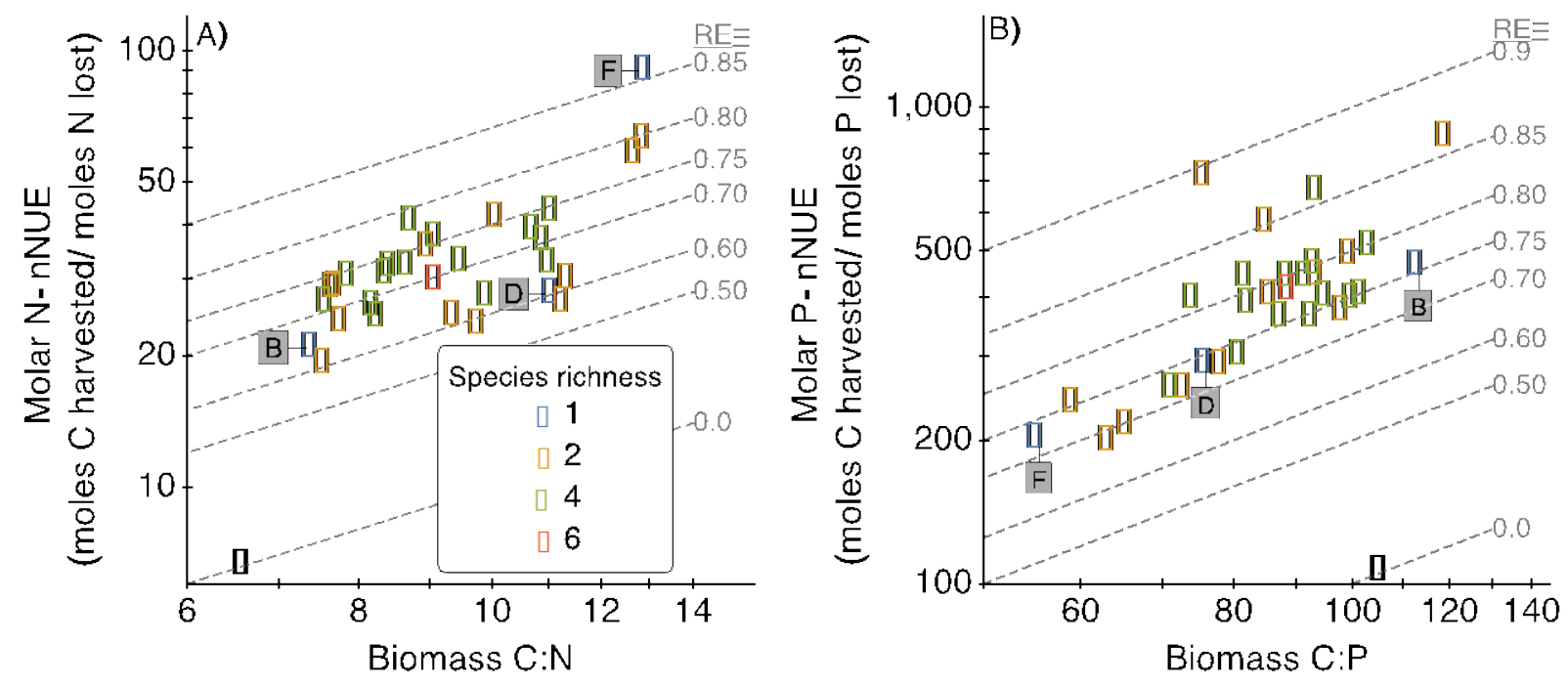

Figure 3. Relationship between net nutrient-use efficiency and biomass stoichiometry for N (A) and P (B). The gray dashed lines represent increasing levels of recovery efficiency (RE). Black stars denote the Redfield ratio for both axes (C:N:P of 106:16:1). Both axes are log-scaled. General linear models for $\mathrm{N}$ and $\mathrm{P}$ recovery efficiencies did not show significant effects of temperature, species richness, or interactions ( $\mathrm{p}>0.05$, Table $\mathrm{S} 2)$, but there was a significant effect of species composition on recovery efficiency for $\mathrm{N}\left(\mathrm{p}<1 \times 10^{-5}\right)$. Figure $\mathrm{S} 4$ includes fully labeled plots for polycultures and depicts the standard error in nNUE. 

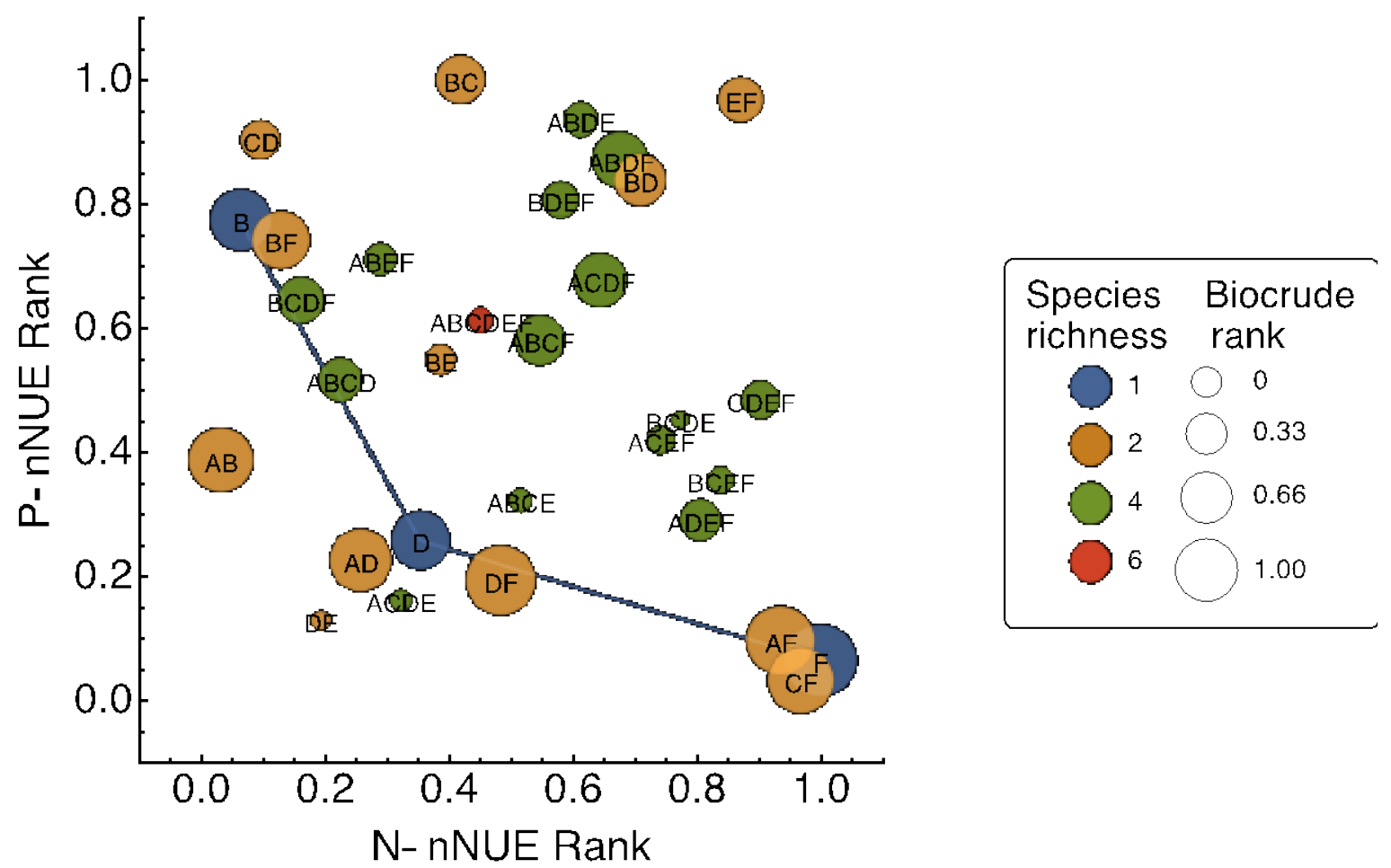

Figure 4. Performance ranks of each species composition in terms of mean N-nNUE, P-nNUE, and biocrude production (bubble diameter). The superior species composition for a given function has rank 1 and the composition with the lowest performance has rank 1/31. Six of the species compositions exhibited low biocrude production (A, C, E, AC, AE, CE) and had insufficient sample coverage to be included in this analysis. Figure S5 shows the bivariate relationships among biocrude productivity and $\mathrm{nNUE}$ for $\mathrm{N}$ and $\mathrm{P}$. 

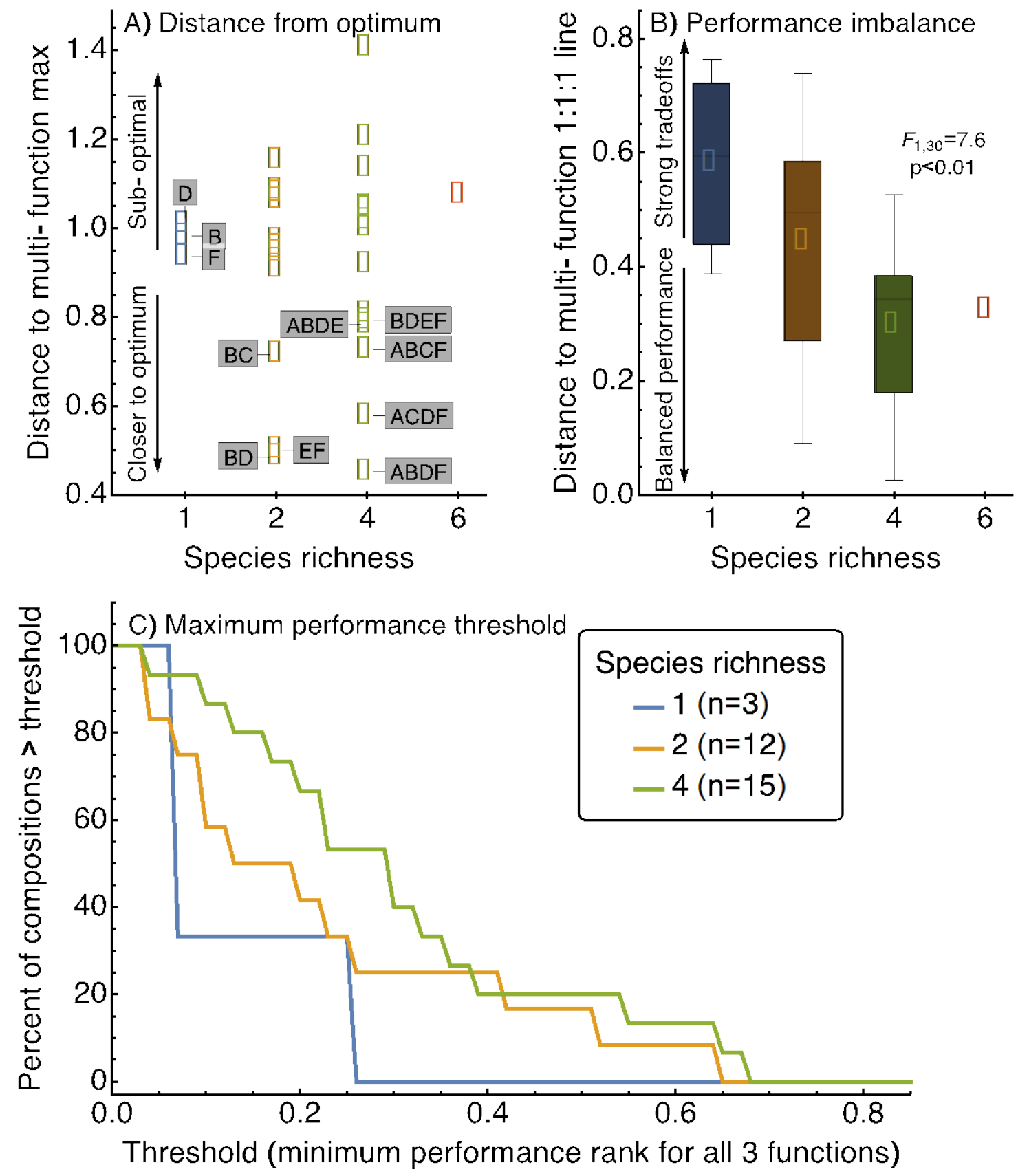

Figure 5. Three aspects of multifunctionality based on multi-functional performance in biocrude production, N-nNUE, and P-nNUE. (A) Distance from optimum is the Euclidean distance between the multi-function performance rank for a given species composition and the maximum possible multi-function performance (rank 1 for all three functions). Larger values indicate poor 
performance in at least one function. (B) Performance imbalance is the Euclidean distance between the multi-function performance rank and balanced performance (1:1:1 line). Larger values indicate strong tradeoffs among the three functions. Edges of boxes represent the $25^{\text {th }}$ and $75^{\text {th }}$ percentiles, whiskers denote the maximum and minimum values, and symbols show the mean value. The inset linear regression test was performed on Euclidean distances with species richness as the independent variable. (C) Maximum performance threshold is the highest rank at which a species composition can perform all three functions simultaneously. This figure shows the proportion of species compositions at each level of species richness that met or exceeded an arbitrary threshold for all three functions. The six-species polyculture is not displayed, but met the 0.16 threshold. 